\title{
SUSTAINABLE DEVELOPMENT OF ANTARCTIC KRILL ENVIRONMENTAL RESOURCES BASED ON SYSTEM DYNAMICS
}

\begin{abstract}
Antarctic krill mainly inhabit the Antarctic Ocean, not far from Antarctica, especially the Weddell Sea, where krill is dense. Marine fisheries have reached new levels, but the topic of sustainable use of marine fishery resources is far from reaching the required levels. In order to study the sustainable development of the Antarctic krill environment, this paper studies the living environment and applicability of Antarctic krill based on system dynamics, and provides some references for the sustainable development of marine resources. Mentioned the use of case analysis method, literature analysis method and other methods to collect data, build a Model, and read and analyse a large number of related literatures through the literature survey method. The experimental results proved that the salinity has a significant effect on the survival rate of Antarctic krill $(p<0.05)$. When the salinity is 34 , the molting frequency reaches its maximum value, which is $70 \%$. It is concluded that the ability of Antarctic krill to adapt to gradual changes in salinity is stronger than that of sudden changes in salinity, and the suitable salinity for survival is $30-42$. With 34 as the basic salinity, when the salinity rises within a certain range, the molting rate of krill will increase, and as the salinity decreases, the molting rate will gradually decrease. This shows that improving the environmental resources of Antarctic krill is an effective method for improving salinity.
\end{abstract}

Keywords: system dynamics, Antarctic krill, resource protection, sustainable development

\section{Introduction}

Antarctic krill usually refers to Antarctic krill. It occupies a central position in the Antarctic ecosystem and is a key species in the Antarctic ecosystem. The reserves of Antarctic krill are very abundant. According to recent acoustic assessments, the biomass of Antarctic krill is between 650 million and 1.0 billion $\mathrm{Mg}\left(10^{6} \mathrm{~g}=\right.$ tonne $)$, and it is conservatively estimated to reach 250 to 600 million tonnes. The biomass accounts for about $50 \%$ of the plankton biomass. The allowable catch is more than double the current fishery output in the world, and it has huge development and utilization potential $[1,2]$. In addition, Antarctic krill is rich in nutrients and is a potentially huge protein pool. China has always emphasised the development and utilization of Antarctic krill, which is the main goal of country's development and utilization of Antarctic biological resources. [3]. The fishing method is mainly trawl, and the production vessel is generally a large tail slide trawl processing vessel. As an important part of China agriculture, fishery has played

\footnotetext{
${ }^{1}$ East China Sea Fisheries Research Institute, Chinese Academy of Fishery Sciences, Shanghai 200090, China, email: ${ }^{a}$ lilz@ecsf.ac.cn, ${ }^{d}$ ecshhl@163.com, ${ }^{e}$ caiyouqiong@163.com, ORCID: LL 0000-0001-5001-7968, HC 0000-0003-3072-511X, HH 0000-0003-0928-3070, YC 0000-0003-4880-3649

${ }^{2}$ School of Economics and Management, Dalian University of Science and Technology, Liaoning 116052, China, email: bannelp1013@hotmail.com, ORCID: 0000-0003-3638-4168

*Corresponding author: ${ }^{\mathrm{c}} \mathrm{chih} @$ ecsf.ac.cn
} 
a pivotal role in promoting Chinese economic development, increasing economic income, optimising dietary structure, and ensuring food safety. However, due to factors such as overfishing and environmental damage, the Antarctic krill industry has been greatly threatened [4].

The method of system dynamics not only requires a systematic scientific theory, but also uses advanced computer technology to simulate and predict the system, which can clearly understand the structure of the system, observe the behaviour of the system intuitively, and make appropriate decisions for decision makers. Currently, the system dynamics method has established a research position on socio-economic problems and is beginning to be widely used for analysis and solution of various problems [5, 6]. The system dynamics method has been achieved in the fields of ecological problems, urban planning problems, and corporate decision-making. It was a great success and further promoted the development of system dynamics. On the whole, system dynamics has been applied to all aspects of society, including the use of a development perspective to solve the problems of global climate and the sustainable development of Antarctic krill environment $[7,8]$.

For the sustainable development of resources, experts at home and abroad also have a lot of research. In foreign countries, Siegel found that the habitat of Antarctic krill is approximately 12.5 million square kilometers through the analysis of relevant data in previous years, and the density varies greatly in different regions. Regarding the dense areas of Antarctic krill distribution, the conclusion is probably the same, that is, dense areas often appear on the edge of the shelf, the edge of the ice shelf and around the island. Found that the immature individuals of Antarctic krill are mainly distributed on the continental shelf and edge, while the mature individuals are mainly distributed in the waters of the continental shelf and the continental slope. The spawning individuals are mainly distributed from the continental slope to the continental uplift, and the spatial density of krill varies with time. In addition, in some areas, such as around South Georgia Islands, although the abundance of Antarctic krill is high, no shrimp eggs, larvae and juveniles are found in this sea area, and this is also regarded as the failure to successfully breed in this sea area [9]. A large number of studies have proved that the abundance of krill is more abundant in the areas around the Antarctic continent, but is very low in other areas. These changes in abundance are inseparable from various bypass systems. The distribution patterns and habits of Antarctic krill (such as vertical movement during day and night) are the result of the interaction of many factors such as long-term evolution, ocean currents and sea ice cover, and not only determined by their own physiological characteristics. Among all the domestic literature studies, the research results of fisheries are few [10]. Because there are many marine fishermen in the country, there are big differences between various sea areas. According to the particularity of fishery rights in China and the national conditions of China, legal countermeasures can be formulated to promote the sustainable utilization of fishery resources by utilising the power gathering system of grassroots cooperative organizations [11, 12]. After studying the support of development finance to Marine fishery, it is found that the main demand of Marine fishery finance in China cannot meet the demand of fishery finance [13].

This paper presents the existing problems, main signs, causes and corresponding solutions in the development and utilization of environmental resources of Antarctic krill, and the deep level caused by the development and utilization of current unsustainable marine fish stocks. Analyse an inadequate analysis of institutional deficiencies. Integrate 
various institutional arrangements related to the development and utilization of marine fishery resources, and build a complete institutional system covering the micro-level property rights system, the meso-level organizational system, and the macro-level government regulation, which will improve the institutional innovation for the sustainable use of environmental resources of Antarctic krill. The implementation efficiency of the system is of great significance.

\section{Sustainable development of Antarctic krill environmental resources}

\section{System dynamics}

System dynamics is a scientific method founded by Professor Forrester of MIT (Massachusetts Institute of Technology) in the United States. At the beginning of its establishment, this method was mainly applied to the management of industrial enterprises, also known as "industrial dynamics". Before constructing the system dynamics Model, the behaviour of the participants in the system should be clarified. The dynamic factors of sustainable development of Antarctic krill environmental resources are analysed in detail from three aspects: government, environment and enterprise [14, 15]. Secondly, a detailed description of the sustainable development goals of environmental resources of Antarctic krill, and finally establish a Model based on "power-target". In system dynamics, the force balance equation of component structure is:

$$
M a+C a+K a=F
$$

The $F$ represents the load matrix, $a$ - the displacement matrix, and $M, C$, and $K$ - the mass, damping and stiffness matrices respectively. It can be divided into two parts, the slave degree of freedom as and the master degree of freedom as, which can be expressed as

$$
a_{s}=T a_{m}
$$

$T$ is the $a_{s} . a_{m}$ order matrix, can be further expressed as

$$
a=\left[\begin{array}{l}
a_{m} \\
a_{s}
\end{array}\right]=\left[\begin{array}{l}
I \\
T
\end{array}\right] a_{m}=T^{*} a_{m}
$$

For functional of unknown functions, there are

$$
\Pi=\int_{\gamma} F\left(u, \frac{\partial u}{\partial k}\right) d \gamma+\int_{\gamma} E\left(u, \frac{\partial u}{\partial x}\right) d \Gamma
$$

In the formula, $u$ is an unknown function; $F$ is a specific operator; $E$ is a specific operator.

The strain matrix is as follows

$$
\begin{gathered}
\mathcal{E}=\left(\begin{array}{l}
\varepsilon_{x} \\
\varepsilon_{y} \\
\varepsilon_{x y}
\end{array}\right)=L u=L N a^{e}=\left[B_{i}, B_{j}, B_{m}\right] a^{e}=B a^{e} \\
\sigma=\left(\begin{array}{c}
\sigma_{x} \\
\sigma_{y} \\
\sigma_{x y}
\end{array}\right)=D \varepsilon=D B a^{e}=S a^{e}
\end{gathered}
$$




$$
S=D B=D\left[B_{i}, B_{j}, B_{m}\right]=\left[S_{i}, S_{j}, S_{m}\right]
$$

In the formula, $B$ is the strain matrix, $L$ is the differential operator, $S$ is the stress matrix, and $D$ is the elastic matrix.

Assuming that the final output is an ideal Model, we can get:

$$
T=f\left(\sum_{i=1}^{n} w_{i} x_{i}-\delta\right)
$$

where $\delta$ is the threshold, assuming that there are $q$ pairs of samples, for the $p$-th sample, the error is defined as:

$$
J(W, b)_{p}=\frac{1}{2}\left\|y^{n}-y\right\|^{2}
$$

Among them, $W$ represents all connection weights, $b$ represents all connection weights in the figure; $y^{n}$ represents the output of the $n^{\text {th }}$ layer, that is, the predicted value of the entire network for the sample, and y represents the true value of the sample. Calculate the average losses for the entire sample set, and then perform a uniform gradient descent, there are:

$$
J(W, b)=\frac{1}{q} \sum_{p=1}^{q} J(W, b)
$$

Find the partial derivatives and find out their respective contributions to the final error. This process can be expressed by the following formula:

$$
\begin{gathered}
w_{i j}^{(l)}=w_{i j}^{(l)}-\operatorname{lr} \frac{\partial(j(W, b))}{\partial w_{i j}^{(l)}} \\
l r=\sigma(t)^{2}=w_{1}(t) \cdot w_{2}(t) \cdot\left(u_{1}(t)\right)-u_{1}(t)^{2}
\end{gathered}
$$

Among them, $t$ is the threshold, $f(x)$ is the fitness function, $w_{1}(t)$ is the number of nodes less than the threshold, and $w_{2}(t)$ is the number of nodes greater than the threshold. Generate a random number in the interval, and select the individual corresponding to the area where the random number belongs.

\section{System dynamics modelling}

"System" is a common term. For many years, scholars in many fields have done detailed research on the concept and characteristics of the system. Generally speaking, a system is a complex collection composed of various elements, and each element in the system has mutual influence and interaction, which together form a whole. The most famous feature of this system is that the overall performance of each element is better than the sum of the performance of each element. The term "Model" is also commonly known. Regarding the definition of the Model, it believes that the Model is a set of rules and relationships that describe certain things [16].

In layman's terms, a Model is an abstraction of the research object and a generalization of the research system [17]. There is an inevitable correspondence between the Model and the system. But although the existing systems are the same, but the modellers are different 
or the modellers pay attention to different angles and problems, the abstracted Model is all different. Therefore, modelling should consider the researched system and the problem to be solved, and Model according to the needs. Specifically, you need to consider the degree of similarity between the abstract Model and the objectively existing system, the degree of fit with the modelling goals, and the degree of data availability [18].

The modelling of system dynamics includes the following steps:

1) Clarify the research problem and determine the boundary of the system

The first and most important step in modelling is to clarify what the research problem is, what problem you are most concerned about, the problem you want to solve, and the goal you want to achieve. What is it? Clear goals are oriented and keep research in the right direction; unclear goals can make people difficult to understand, the Model built is too small or too large, or there are suspicious and repeated behaviours in the process of research.

Determining the boundary of the system on the basis of clarifying the problem is the key to establishing the Model. Things in the world are interconnected. If all the factors are to be included in the research Model, the system will be very large and bloated, with no focus. Therefore, the boundary of the system should be determined according to the research problem, and the factors closely related to the problem to be researched should be included for key investigation. Specifically, we must determine the key variables, including endogenous variables, exogenous variables, etc., and determine the time limit of the research.

2) Propose dynamic hypotheses

This step is the focus of the modelling process. It is necessary to use existing theories and research to explain the current problems, and establish hypotheses based on the internal structure and dynamic behaviour of the system to be observed. The hypothesis established can be represented in the form of a drawing. The causal loop diagram is a common way to reflect the system. The diagram contains variables related to the system, and the variables are connected by arrows. It is worth noting that the variables in the causal chain are not simply related, but must be causal. Each causal chain has either positive or negative polarity, a positive causal chain means that the cause increases, the result will increase, the cause decreases, and the result will also decrease. For example, the relationship between product quality and sales volume is a positive chain of causal relationships. Conversely, a negative causal chain means that as the cause increases, the result decreases, and as the cause decreases, the result increases

3) Carry out parameter estimation

The estimation of the parameters of the Model equation and the establishment of the Model equation are the key to maintaining the authenticity of the entire system behaviour. The estimation of the parameters can be determined using the data of the state variables and rate variables of the system. At the same time, establish the state equation, rate equation and auxiliary equation of the system, and give the initial value of the system.

4) Model checking

The main function of this step is to test and verify the established Model to verify the adaptability, physical structure, robustness and sensitivity of the Model, including the Model's boundary suitability test, validity test, extreme condition test and sensitivity test etc., to verify whether the established Model can stably reflect the actual system. 
5) Model simulation test

Using the collected data, use professional software such as Vensim to simulate the Model and interpret the simulation results. In short, the modelling of system dynamics is the prerequisite and key to the research of the problem. The modelling of system dynamics is not accomplished overnight, but needs to be modified repeatedly to finally determine the appropriate Model, and to effectively solve the problem and guide decision-making.

\section{Antarctic krill}

As a potential and huge protein reservoir for humans, the commercial development of Antarctic krill has long attracted people's attention. So far, countries engaged in Antarctic krill production include Chile, Germany, Japan, Latvia, South Korea, Panama, Poland, the former Soviet Union, Russia, South Africa, Ukraine, Britain, Uruguay, the United States, Vanuatu, Norway, China, etc. So far, the total production of krill has exceeded 6 million tonnes, and more than $90 \%$ of it comes from the Scotia waters on the west side of the Atlantic Ocean.

Antarctic krill have a habit of moving vertically day and night, are mainly distributed in the deep sea during the day, and rise to the upper waters to feed at night. It is generally believed that the main reason for Antarctic krill sinking during the day is to avoid predators, and it may also be related to temperature and light. So far, there is no unified conclusion about the vertical movement of Antarctic krill day and night. There is a certain difference in the size of krill clusters between day and night, and the night cluster time is longer than during the day.

The distribution of Antarctic krill is a collection of time and space. The abundance and density of krill in the Antarctic Peninsula and its adjacent areas show clear seasonal changes. People have been committed to studying the reasons that affect the distribution, biomass levels and resource dynamics of Antarctic krill, and analysed various related factors, such as ocean currents, sea ice, temperature, chlorophyll, predators, light, and food. Recently, echo detection has been used to explore the distribution and abundance of krill. This method has greatly improved researchers' understanding of the abundance patterns of krill clusters of various sizes.

Even so, there are still few studies to get a clear relationship between the various habits of Antarctic krill and environmental factors, just as people have not found the exact effect of temperature, salinity and dissolved oxygen on the krill colony. Sometimes the abundance of krill in a certain area shows a certain relationship with the environment in a certain year, but this relationship will change in different years or in different regions, so there is no single factor or set of factors it can be used to accurately predict the distribution and resource dynamics of krill. But on the other hand, the reason why it is difficult to find a certain specific law is precisely because of the elusive combination of various factors in the complex Southern Ocean environment. However, it cannot be denied that environmental factors play a very important role in the distribution and abundance of Antarctic krill. Early studies showed that the overall distribution of Antarctic krill was consistent with the distribution of winter sea ice. Later, a conceptual Model of the growth behaviour of krill in winter was established. Sea ice has a huge impact on the growth of phytoplankton, thus gradually verifying sea ice. It plays a very important role in the life history of Antarctic krill. Antarctic krill is shown in Figure 1. 


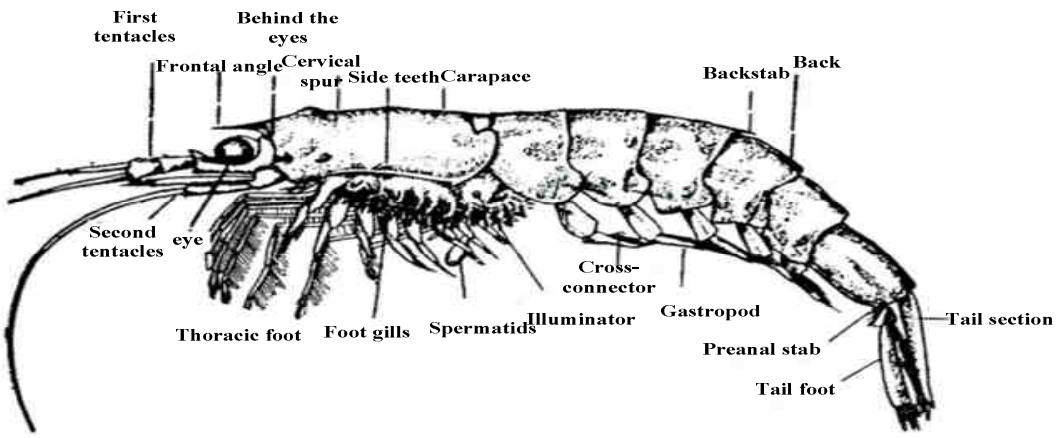

Fig. 1. Antarctic krill diagram

Our country's commercial development of Antarctic krill is relatively late. The Ministry of Agriculture established the "Development and Utilization of Antarctic Marine Biological Resources" project in 2010, and started Chinese commercial development of Antarctic krill. Chinese main fishing areas in Antarctica are the waters around the South Shetland Islands in Area 48.1 and the waters around the South Orkney Islands in Area 48.3. In early 2017, China conducted exploratory surveys in Area 58, but the development of fisheries did not take place for very long. The production of krill in China has basically shown an upward trend year after year. However, due to the fishing technology and the inability to fully grasp the law of the influence of various factors on Antarctic krill, the fishing level of Antarctic krill in China needs to be improved. Therefore, studying the temporal and spatial distribution of Antarctic krill fishing grounds and fishing grounds and their relationship with time and space [19], marine environment and fishing factors is of great significance for in-depth study of the formation mechanism of environmental characteristics of Antarctic krill fishing grounds and resource development and utilization.

\section{Experiments on sustainable development of environmental resources}

\section{Subjects}

Antarctic krill were selected as the experimental objects with a body length of 30-45 mm, high mobility and no defect. The experimental water is all taken from external natural seawater, the dilution water is freshwater water, and the salt of high-concentration seawater is naturally generated by the evaporation of seawater. Use an electronic salt meter to confirm the salt concentration of the test water, and use a thermometer to measure the temperature. The holding container is a $500 \mathrm{~mL}$ translucent plastic bottle.

\section{Experimental method}

In the experiment, three sets of sharp changes and phase changes of salt concentration, and salt recovery after phase changes were set up. The experimental settings suddenly changed $14,18,22,26,30,34,38,42$, a total of 8 salt gradients, as a $500 \mathrm{~mL}$ translucent plastic bottle of the experimental container. After placing the collected shrimp samples in natural seawater for 24 hours and temporarily storing them, put 2 fresh shrimps in each 
transparent bottle, prepare 6 parallel samples, and implement them under static water conditions. In order to more accurately grasp the impact of rapid changes in salt concentration on Antarctic krill [20], the observation frequency was divided into 3 hours on the first day and every 12 hours thereafter, and the living conditions and molting conditions in Antarctica were recorded.

\section{Establish a model evaluation index system}

The evaluation index is a specific evaluation item determined according to some evaluation goals, which can reflect some basic characteristics of the evaluation object $[21,22]$. The index is specific and measurable, and it is the observation point of the goal. Definite conclusions can be drawn through actual observation of the object. Generally speaking, the evaluation index system includes three levels of evaluation indexes: they are the relationship between gradual decomposition and refinement. Among them, the firstlevel evaluation indicators and the second-level evaluation indicators are relatively abstract and cannot be used as a direct basis for evaluation. The third-level evaluation indicators should be specific, measurable and behaviour-oriented, and can be used as a direct basis for evaluation. The evaluation indicators are shown in Table 1.

System indicator drawing

\begin{tabular}{|c|c|c|c|}
\hline Serial number & Variable name & Variable unit & Variable type \\
\hline 1 & Output value & 100 million yuan & State variables \\
\hline 2 & Creativity & Pieces & State variables \\
\hline 3 & Practitioners & Ten thousand people & State variables \\
\hline 4 & Invest in & 100 million yuan & Auxiliary variable \\
\hline 5 & Benefit conversion rate & $\%$ & Auxiliary variable \\
\hline 6 & Application level & - & Auxiliary variable \\
\hline
\end{tabular}

\section{Data processing}

All data analysis in this article uses SPSS19.0 (Statistical Program for Social Sciences), statistical test uses two-sided test, significance is defined as 0.05 and $p<0.05$ is considered significant. The statistical results are displayed as mean \pm standard deviation $(x \pm S D)$. When the test data complies with the normal distribution, the double- $T$ test is used for comparison within the group, and the independent sample $p$ test is used for comparison between the groups. If the regular distribution is not sufficient, two independent samples and two related samples will be used for inspection.

\section{Sustainable development of environmental resources}

\section{Antarctic krill fishing}

First of all, we have recently obtained relevant statistics for the countries that have obtained fishing permits in recent years. As shown in Table 2, in recent years, China has gradually become an Antarctic krill fishing country.

In recent years, the development of marine fishery operation structure mainly reflects the following two characteristics: First, fishing grounds are expanding to the sea. With the mechanization, large-scale, and steel of fishing vessels, the fishing area gradually expands to the sea. In recent years, a central fishing ground has been formed in the sea area. 
The economic fish and shrimp resources in this sea area are relatively rich, and the fishing ground environment and operating conditions are excellent [23]. It is a perennial production fishing ground. The second is that as fishing grounds move out, the structure of fishing operations has also changed. By the end of 2020, the catches of both towing operations and shrimp fishing operations have accounted for more than $60 \%$ of the catch. We make statistics on fishermen and fishing income, as shown in Figure 2.

Vessels holding permits

\begin{tabular}{|c|c|c|c|c|c|c|c|c|}
\hline & $\mathbf{2 0 1 3}$ & $\mathbf{2 0 1 4}$ & $\mathbf{2 0 1 5}$ & $\mathbf{2 0 1 6}$ & $\mathbf{2 0 1 7}$ & $\mathbf{2 0 1 8}$ & $\mathbf{2 0 1 9}$ & $\mathbf{2 0 2 0}$ \\
\hline China & 0 & 0 & 0 & 2 & 5 & 5 & 6 & 6 \\
\hline Chile & 1 & 1 & 1 & 0 & 1 & 1 & 1 & 1 \\
\hline Germany & 0 & 0 & 0 & 0 & 0 & 0 & 1 & 1 \\
\hline Japan & 1 & 1 & 2 & 1 & 1 & 1 & 1 & 1 \\
\hline Korea & 3 & 2 & 3 & 3 & 2 & 3 & 3 & 4 \\
\hline Norway & 1 & 2 & 2 & 3 & 3 & 3 & 3 & 4 \\
\hline Poland & 1 & 1 & 1 & 1 & 1 & 1 & 1 & 0 \\
\hline
\end{tabular}

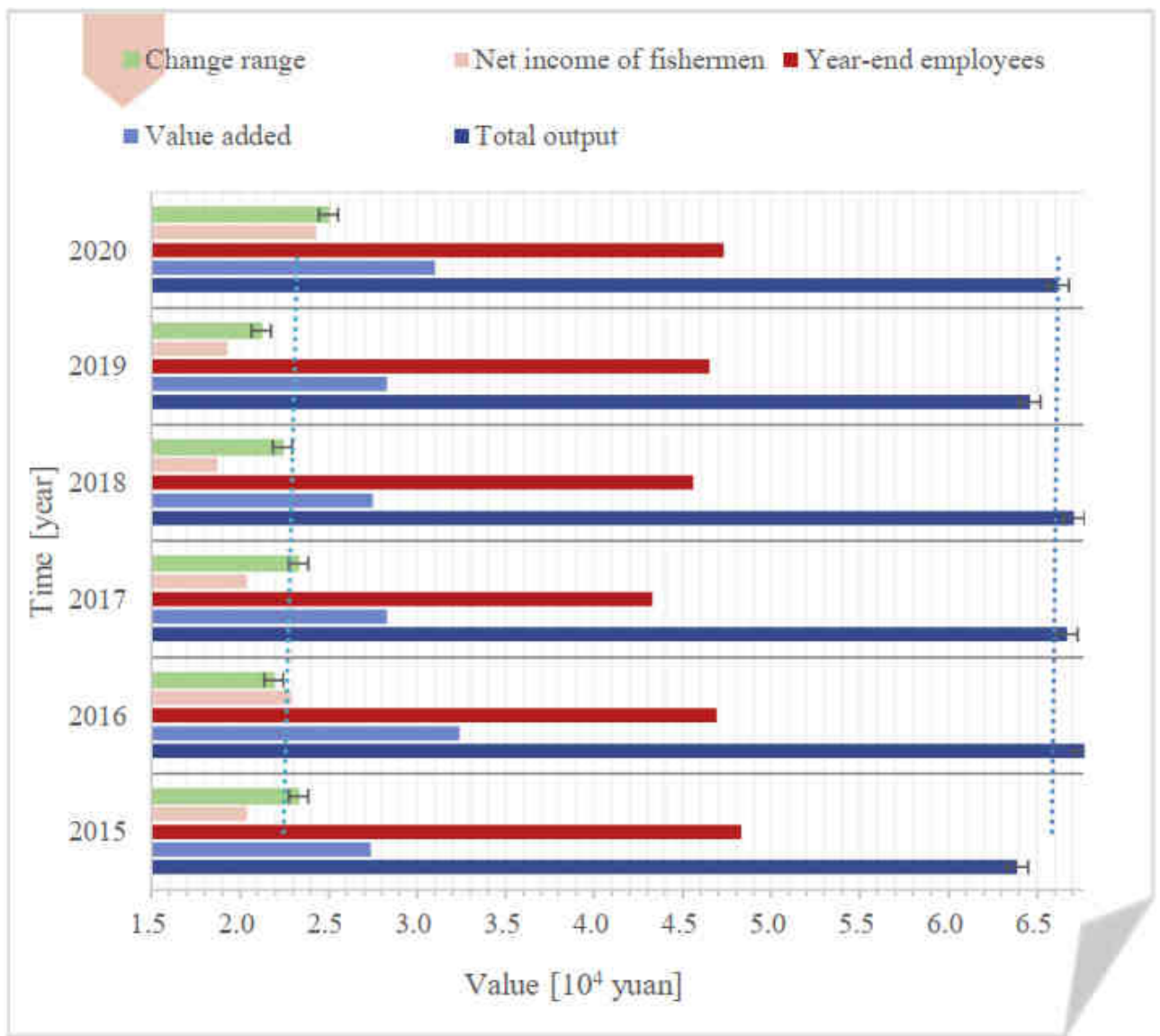

Fig. 2. Parameters of marine fisheries 
Judging from the data so far, the total output of ocean fisheries has basically shown a steady and increasing trend, the added value of ocean fisheries has increased year by year, the number of employees in ocean fisheries has been basically stable, and the per capita net income of fishermen has also increased year by year. We have studied the trawl net for catching shrimp and found that the amount of catch is related to the trawl net, as shown in Figure 3.

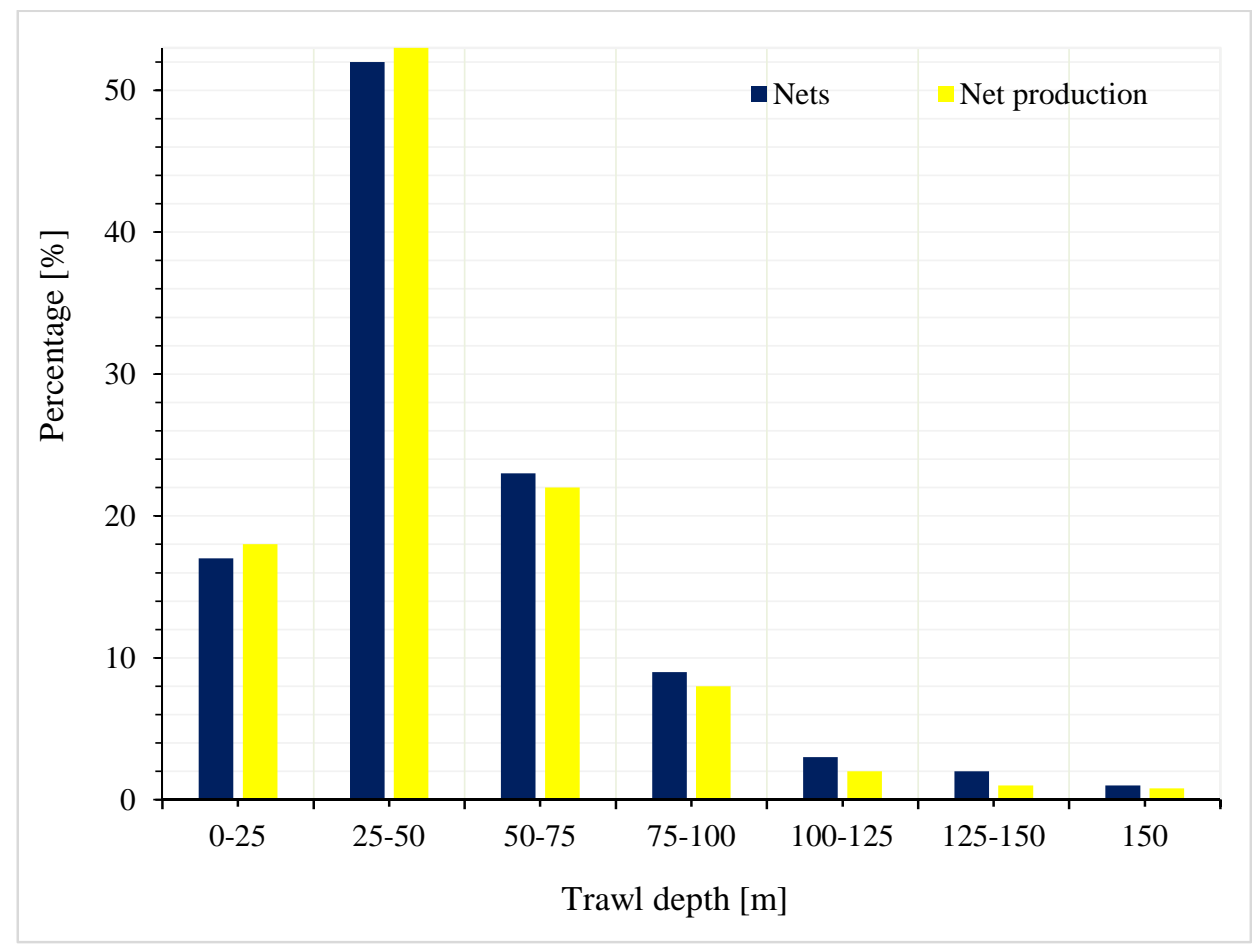

Fig. 3. Number of trawls and yields at different depths

The average stock level of Antarctic krill depends on the depth of the troll. According to the statistical analysis of fishery survey data, it can be concluded that the mean catch per unit fishing effort of Antarctic krill gradually decreases as the depth of trawl increases. There are significant differences in the distribution of catches per unit of fishing effort in different trawl water depths.

\section{Effect of salinity on Antarctic krill}

We used statistics on the survival of Antarctic krill under different salinities, and compared their survival time in salt water of different solubility, as shown in Table 3.

After 6 hours of salinity, when the salinity reached $14 \mathrm{mg} / \mathrm{L}$, the individual mortality of krill was nearly $100 \%$. In 12 hours, the mortality rate of the salt group reached $100 \%$ of $14,18,22 \mathrm{mg} / \mathrm{L}$, accounting for $36 \%$ of the total. When the amount is $30 \mathrm{mg} / \mathrm{L}$, the mortality of krill within 24 hours is $0 \%$. Then, during the ongoing containment process, the mortality rate of the remaining krill was very low. A single-cause analysis showed that 
the effect of salt on the mortality rate of the krill was still significant $(p<0.05)$. In other salt regions, with the onset of adaptation, the mortality rate of krill is extremely low for a period of time.

Table 3

Survival rate [\%] of shrimp under different salinity

\begin{tabular}{|c|c|c|c|c|c|c|c|c|}
\hline Time & $\mathbf{1 4} \mathbf{~ m g / L}$ & $\mathbf{1 8} \mathbf{~ m g} / \mathbf{L}$ & $\mathbf{2 2} \mathbf{~ m g} / \mathbf{L}$ & $\mathbf{2 6} \mathbf{~ m g} / \mathbf{L}$ & $\mathbf{3 0} \mathbf{~ m g} / \mathbf{L}$ & $\mathbf{3 4} \mathbf{~ m g} / \mathbf{L}$ & $\mathbf{3 8} \mathbf{~ m g} / \mathbf{L}$ & $\mathbf{4 1} \mathbf{~ m g / L}$ \\
\hline $3 \mathrm{~h}$ & 30 & 70 & 100 & 100 & 100 & 100 & 90 & 10 \\
\hline $6 \mathrm{~h}$ & 0 & 20 & 90 & 100 & 100 & 100 & 90 & 10 \\
\hline $9 \mathrm{~h}$ & 0 & 0 & 50 & 90 & 100 & 100 & 80 & 0 \\
\hline $12 \mathrm{~h}$ & 0 & 0 & 0 & 80 & 100 & 100 & 70 & 0 \\
\hline $15 \mathrm{~h}$ & 0 & 0 & 0 & 70 & 100 & 100 & 50 & 0 \\
\hline $18 \mathrm{~h}$ & 0 & 0 & 0 & 70 & 100 & 90 & 50 & 0 \\
\hline $21 \mathrm{~h}$ & 0 & 0 & 0 & 70 & 100 & 70 & 30 & 0 \\
\hline $24 \mathrm{~h}$ & 0 & 0 & 0 & 70 & 100 & 70 & 30 & 0 \\
\hline
\end{tabular}

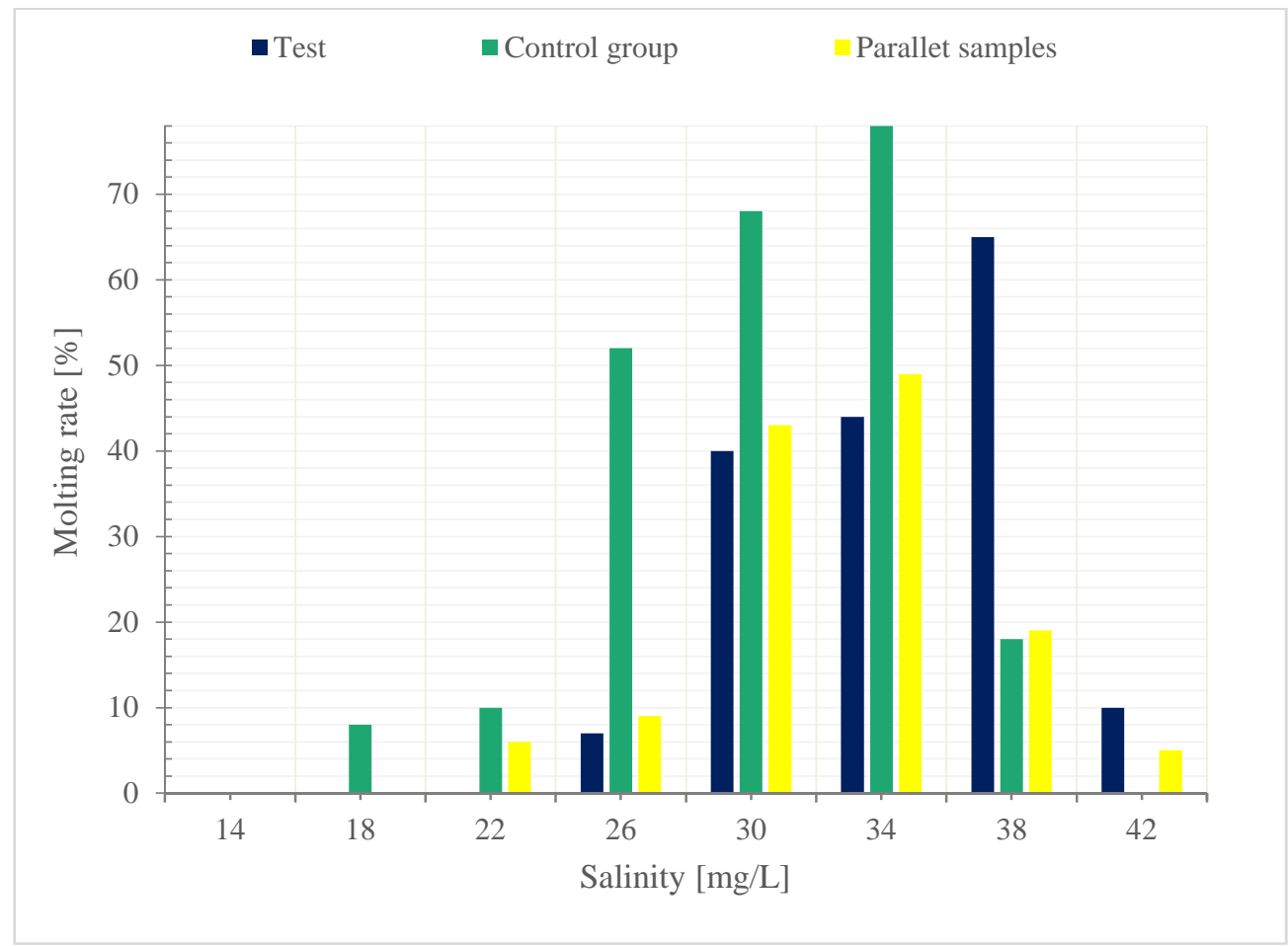

Fig. 4. Moult rate of Antarctic shrimp

As shown in Figure 4, within 24 hours, there were no molting krill individuals in each salinity group. In the subsequent holding experiment, only the salinity groups of $26.0 \pm 0.4$, $30.0 \pm 0.4,34.0 \pm 0.4,38.0 \pm 0.4$ and $42.0 \pm 0.4$ showed molting. The molting rate was highest when the salinity was 34.0 , accounting for $39.3 \%$ of the total molting individuals. When the salinity is 30.0-38.0, the molting rate of krill is higher, accounting for $88.2 \%$ of the total krill molting individuals. From the results of the sudden change in salinity 
experiment, when the salinity of the water body tends to the high limit, the molting speed of the krill increases, and when the salinity decreases below the bottom limit or rises above the high limit, the krill will no longer molt.

\section{Environmental impact}

In order to test the impact of the environment on Antarctic krill, we first analysed the Antarctic krill living environment, and then changed the breeding environment to compare the production status of Antarctic krill. The Antarctic krill living environment is shown in Figure 5.

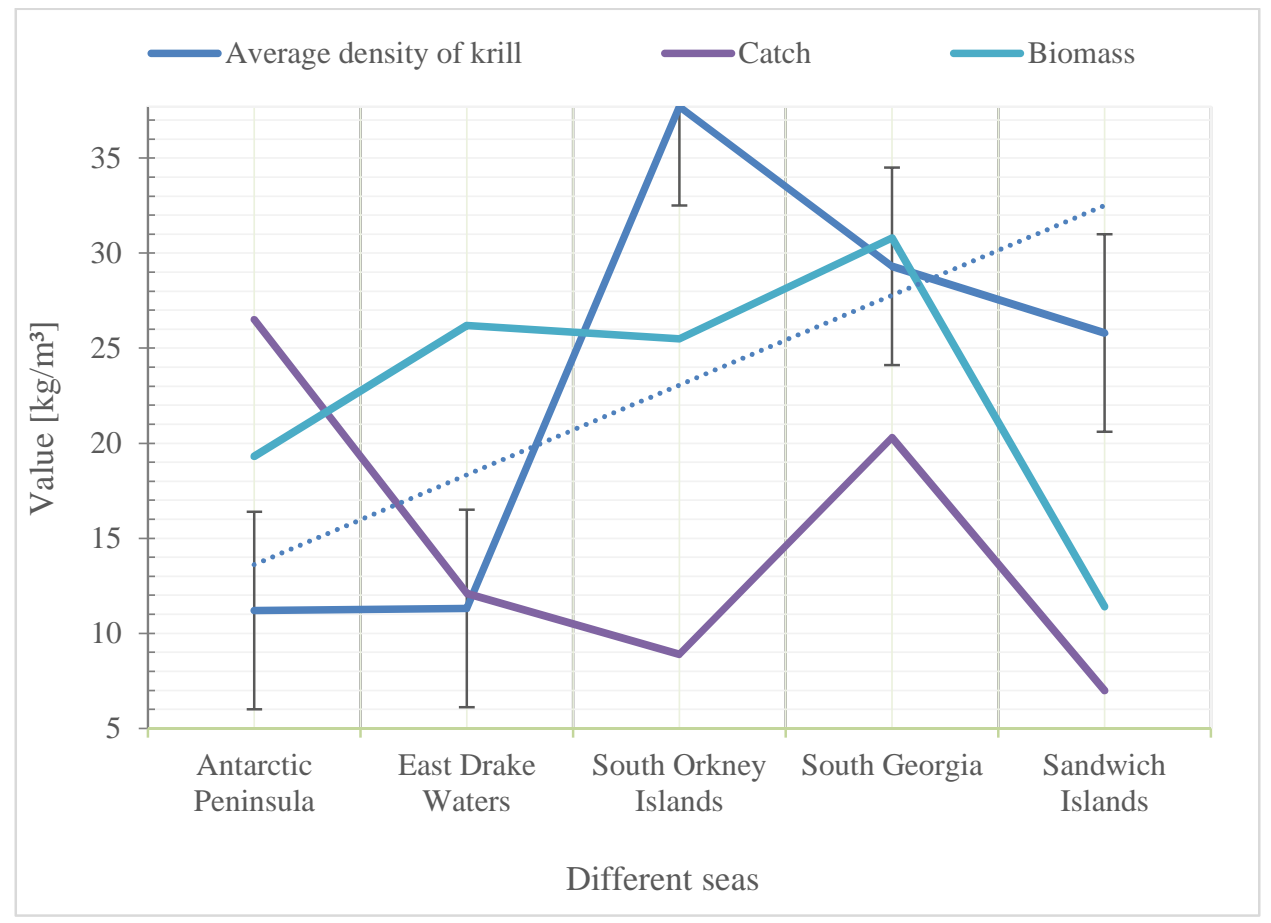

Fig. 5. Distribution of Antarctic krill

From Figure 6, we can see that the production of Antarctic krill is very rich, the living area is relatively wide, and the sea area is more complicated. Generally speaking, the value of the catch per unit fishing effort of Antarctic krill shows a single peak to the left. Distribution, the average catch value per fishing effort of most nets is distributed on the smaller side, and the larger catch value per fishing effort occupies a small part. After changing the environment, we conducted related experiments on the state of live shrimp in different ecological environments, as shown in Figure 6.

From Figure 6 we can see that the various technical indicators of Antarctic krill are completely different under different levels of pollution. The technical indexes of Antarctic krill under no pollution or mild pollution were $20 \%$ better than those under severe pollution, which shows that for Antarctic krill, survival in an ecological environment can 
effectively maintain its sustainable growth, which is also conducive to the subsequent development of marine fisheries.

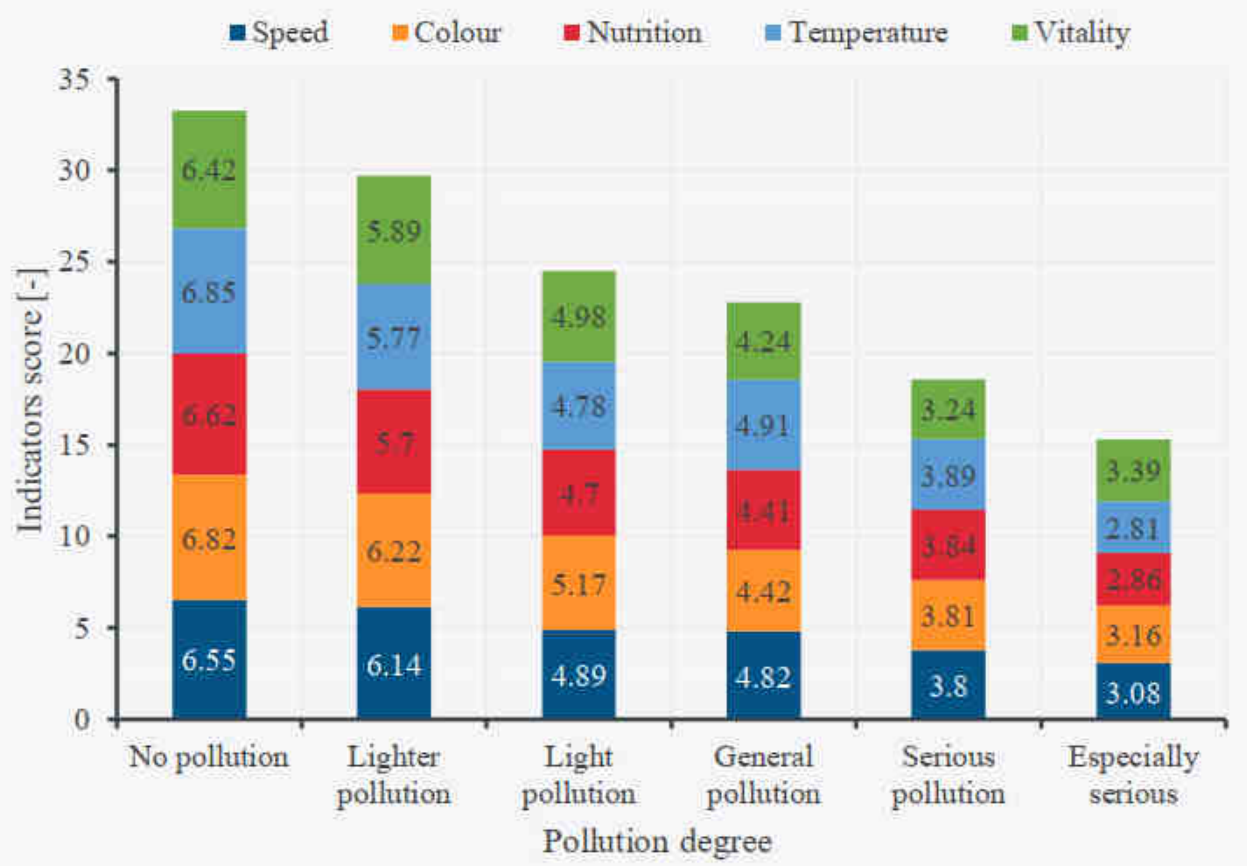

Fig. 6. The effect of pollution on Antarctic krill

\section{Conclusion}

The ecological environment of water bodies, especially the Antarctic ecological environment, is the basis for the survival of aquatic organisms. Protecting the marine ecological environment not only provides living conditions suitable for the habitat and breeding of aquatic organisms, but also provides humans with a beautiful and healthy living environment. It is necessary to adhere to the concept and policy of "prevention first, protection first and paid use", strengthen marine ecological environmental protection and restoration, curb the trend of environmental deterioration, and restore ecological balance. This article is only a preliminary analysis of the relationship between the distribution of Antarctic krill resources and time and space, marine environment and fishing factors. The data used is relatively small, the survey area is small, and the time is short. It is impossible to use the large-scale data for many years to study the amount of resources. Therefore, for the systematic analysis of the distribution of Antarctic krill resources and the level of biomass Research is somewhat restrictive. In the experiment of living body holding, due to the lack of corresponding equipment, it is impossible to control the changes of variables, such as temperature and salinity, particularly accurately. The amount of live krill is relatively small, so the number of live krill is also a limiting condition. Need to further strengthen efforts in the future. 


\section{Acknowledgements}

This work was supported by the National Key R\&D Program of China (No. 2017YFC1600706); Central Public-interest Scientific Institution Basal Research Fund, CAFS (No. 2020TD68), Natural Science Foundation of Shanghai (18ZR1449900). We highly appreciated that the 36th Antarctic expedition of China supported the samples of Antarctic krill.

\section{References}

[1] Peng D, Yang Q, Yang HJ, Liu H, Zhu Y, Mu Y. Analysis on the relationship between fisheries economic growth and marine environmental pollution in China's coastal regions. Sci Total Environ. 2020;713:136641.1-136641.9. DOI: 10.1016/j.scitotenv.2020.136641.

[2] Cheung W, Reygondeau G, Frlicher TL. Large benefits to marine fisheries of meeting the $1.5^{\circ} \mathrm{C}$ global warming target. Science. 2016;354(6319):1591-4. DOI: 10.1126/science.aag2331.

[3] Chen YY, Zheng WZ, Li WB, Huang YM. The robustness and sustainability of port logistics systems for emergency supplies from overseas. J Advanced Transportation. 2020; DOI: 10.1155/2020/8868533.

[4] Hart P. Global atlas of marine fisheries: a critical appraisal of catches and ecosystem impacts. J Fish Biol. 2017;91(6):1750-1. DOI: 10.1111/jfb.13501.

[5] Essington TE, Ciannelli L, Heppell SS, Levin PS, Mcclanahan TR, Micheli F, et al. Empiricism and modeling for marine fisheries: advancing an interdisciplinary science. Ecosystems. 2017;20(2):1-8. DOI: 10.1007/s10021-016-0073-0.

[6] Grubljesic T, Coelho PS, Jaklic J. The shift to socio-organizational drivers of business intelligence and analytics acceptance. J Organizational End User Computing. 2019;31(2):37-64. DOI: 10.4018/JOEUC.2019040103.

[7] Lozano A, Heinen JT. Identifying drivers of collective action for the co-management of coastal marine fisheries in the gulf of Nicoya, Costa Rica. Environ Manage. 2016;57(4):759-69. DOI: 10.1007/s00267-015-0646-2.

[8] Tsai SB, Riga S, Lin YC, Quan C. Discussing measurement criteria and competitive strategies of green suppliers from a green law perspective. Proc Institution Mechanical Engineers. Part B: J Manufacture. 2015;229(S1):135-45. DOI: 10.1177/0954405414558740.

[9] Hughes TP, Cameron DS, Chin A, Connolly SR, Day JC, Jones GP, et al. A critique of claims for negative impacts of Marine Protected Areas on fisheries. Ecol Applications. 2016;26(2):637-41. DOI: 10.1890/15-0457.

[10] Ertor-Akyazi P. Contesting growth in marine capture fisheries: the case of small-scale fishing cooperatives in Istanbul. Sust Sci. 2020;15(1):45-62. DOI: 10.1007/s11625-019-00748-y.

[11] Pita P, Villasante S. The building of a management system for marine recreational fisheries in Galicia (NW Spain). Ocean Coastal Manage. 2019;169:191-200. DOI: 10.1016/j.ocecoaman.2018.12.027.

[12] Asina FNU, Brzonova I, Kozliak E, Kubatova A, Ji Y. Models for forecasting growth trends in renewable energy. Renew Sust Energy Rev. 2017;77:1169-78. DOI: 10.1016/j.rser.2017.03.098.

[13] David RR, Rodriguez J, Malak DA, Nastasi A, Hernandez P. Marine protected areas and fisheries restricted areas in the Mediterranean: assessing "actual" marine biodiversity protection coverage at multiple scales. Marine Policy. 2016;64:24-30. DOI: 10.1016/j.marpol.2015.11.006.

[14] Kitouni I, Benmerzoug D, Lezzar F. Smart agricultural enterprise system based on integration of internet of things and agent technology. J Organizational End User Computing. 2018;30(4):64-82. DOI: 10.4018/JOEUC.2018100105.

[15] Marszałek M, Kowalski Z, Makara A. The possibility of contamination of water-soil environment as a result of the use of pig slurry. Ecol Chem Eng S. 2019;26(2):313-30. DOI: 10.1515/eces-2019-0022.

[16] Biswas S, Devi D, Chakraborty M. A hybrid case based reasoning model for classification in internet of things (iot) environment. J Organizational End User Computing. 2018;30(4):104-22. DOI: 10.4018/JOEUC.2018100107

[17] Bakker YW, Koning JD, Tatenhove JV. Resilience and social capital: the engagement of fisheries communities in marine spatial planning. Marine Policy. 2019;99:132-9. DOI: 10.1016/j.marpol.2018.09.032.

[18] Ibrahim M, El H, Sherif B, Mohamed E, Reham RM. Improved feature selection model for big data analytics. IEEE Access. 2020;8(1):66989-7004. DOI: 10.1109/ACCESS.2020.2986232.

[19] Lv Z, Li X, Lv H, Xiu W. BIM Big data storage in Webvrgis. IEEE Trans Industrial Informatics. 2019. DOI: 10.1109/TII.2019.2916689. 
[20] Xu XZ, Zhang N, Zhou Y, Wang Y, Wang ZH. The effects of NaI, KBr and KI salts on the vapor-liquid equilibrium of $\mathrm{H}_{2} \mathrm{O}+\mathrm{CH}_{3} \mathrm{OH}$ system. Frontiers Chemistry. 2020. DOI:10.3389/fchem.2020.00192.

[21] Sim K, Yang J, Lu W, Gao X. MaD-DLS: Mean and deviation of deep and local similarity for image quality assessment. IEEE Trans Multimedia. 2020;1-1. DOI: 10.1109/TMM.2020.3037482.

[22] Sołowski G, Konkol I, Cenian A. Perspectives of hydrogen production from corn wastes in Poland by means of dark fermentation. Ecol Chem Eng S. 2019;26(2):255-63. DOI: 10.1515/eces-2019-0031.

[23] Pavelkova A, Stejskall V, Voloscukova O, Nosek J. Cost-effective remediation using microscale ZVI: comparison of commercially available products. Ecol Chem Eng S. 2020;27(2):211-24. DOI: 10.2478/eces-2020-0014. 